\title{
Concentration profiles of Personal Care Products in swimming pools
}

\author{
Anna Lempart ${ }^{1, *}$,Edyta Kudlek $^{1}$, and Mariusz Dudziak ${ }^{1}$ \\ ${ }^{1}$ Silesian University of Technology, Institute of Water and Wastewater Engineering, Konarskiego 18, \\ 44-100 Gliwice, Poland
}

\begin{abstract}
Concentration profiles of Personal Care Products (PCPs) in outdoor and indoor swimming pools are compared. The difference in the obtained chromatographs were observed. The quantitative analysis show that the frequency of occurrence and concentrations of two selected compounds (BZ-3 and BZ-8) from PCPs are higher in indoor swimming pools than in outdoor swimming pools. The obtained in this work results for swimming pools located in Poland differ from those received in Spain in previous work.
\end{abstract}

\section{Introduction}

Swimming pools are becoming more and more popular among people enjoying a healthy lifestyle and active leisure. Swimming is considered to be the best form of activity. It improves blood circulation, strengthens muscles and shapes the figure. Therefore it is not surprising that swimming pools are developing dynamically. While the number of people using the swimming pool is increasing year by year, the amount of pollutants entering the water also increases. The World Health Organization (WHO) identifies three health threats to pool users [1]. In addition to injuries or drowning, these are microbiological threats and hazards resulting from the exposure to chemical substances, including poisoning as a result of long-term exposure to chemicals. It may result from contact, inhalation or consumption of chemically contaminated water, consumption of algae toxins or inhalation of chemically contaminated air.

Chemical compounds may be introduced into swimming pool water in many ways, among others by swimmers (for example as products of their metabolic activity), together with source water, from swimming pool basin surroundings or as deliberate exploitation additives (disinfectants, coagulants, biocides, algaecides, etc.).

An average swimmer visits a pool 72.6 times/year [2]. Many chemical compounds, including detergents, cosmetics ingredients or flame retardants are present on the swimmer's skin, hair and swimsuit during each of these visits. They can accumulate in the swimming pool water. Standard water treatment methods (that are commonly used in swimming pool water treatment installations) have been shown to not completely remove these organic anthropogenic micropollutants from water [3]. It has also been proven that long-term exposure to some of Personal Care Products (PCPs) may cause the negative

\footnotetext{
* Corresponding author: anna.lempart@polsl.pl
} 
health effects [4-7]. PCPs of concern in pool water include mainly compounds capable of absorbing UV radiation, which are the main component of sunscreens [8-13]. Some of them may exhibit estrogenicity and antiandrogenicity [14-19]. There are also concerns about their potential carcinogenicity [20].

Previous works of authors $[21,22]$ have proved the presence of many different PCPs, including aroma compounds (hedione, $\gamma$-decalactone), sunscreens (oxybenzone, dioxybenzone), moisturizers agents (oleic acid) and antioxidants (butylated hydroxytoluene) in swimming pools. Other researchers all over the word [15-23] have been focused on the occurence of UV filters (enzacamene, octyl-methoxycinnamate, $1 \mathrm{H}$-benzotriazole, benzophenones and their metabolites, PABA and its derivatives), parabens (benzyl-, propyl-, butyl-, methyl-, ethyl-, heptyl-, octyl-) and their chlorinated derivatives.

PCPs concentrations found in different swimming pool around the world vary a lot depending on many factors including the type of swimming pool, its dimensions and localization, the type of applied water treatment method and the number of swimmers.

The aim of this work was to compare the concentration profile of Personal Care Products in outdoor and indoor swimming pools located in Poland. The physical and chemical quality parameters of the water met the requirements. In this work, small-molecule micropollutants from the group of UV filters, such as benzophenone-3 and its metabolite, benzophenone- 8 , were determined.

\section{Materials and method}

Samples of volume $100 \mathrm{~mL}$ were collected during 5 weeks in summer 2017 from 4 different indoor pools and 4 different outdoor pools located in Silesia, in Poland. They are listed in the Table 1. From each pool, samples were collected once a week, from 7 different points of swimming pool. The presented results are the arithmetic average of the four replicates of each experiment. For all the cases assigned error (estimated based on the standard deviation) did not exceed $5 \%$ so the results are presented without marking of the ranges of error.

Table 1. The list of tested swimming pools.

\begin{tabular}{|c|c|c|c|c|c|}
\hline \multirow{2}{*}{$\begin{array}{c}\text { Type of swimming } \\
\text { pool }\end{array}$} & \multicolumn{3}{|c|}{ Main processes of the pool water treatment system } \\
\cline { 2 - 6 } & Coagulation & Filtration bed type & Disinfection & $\begin{array}{c}\text { Frequency } \\
\text { of full water } \\
\text { replacement }\end{array}$ \\
\hline \multirow{4}{*}{ Indoor } & Sport & Yes & $\begin{array}{c}\text { gravel+sand+ } \\
\text { hydroanthracite }\end{array}$ & $\begin{array}{c}\text { sodium hypochlorite } \\
\text { + UV lamp }\end{array}$ & 1 year \\
\cline { 2 - 6 } & Jacuzzi & Yes & \begin{tabular}{c} 
gravel+sand+ \\
hydroanthracite \\
\cline { 2 - 6 }
\end{tabular} & $\begin{array}{c}\text { sodium hypochlorite } \\
\text { + UV lamp }\end{array}$ & 1 year \\
\cline { 2 - 6 } & Children's & Yes & $\begin{array}{c}\text { gravel+sand+ } \\
\text { hydroanthracite }\end{array}$ & $\begin{array}{c}\text { sodium hypochlorite } \\
\text { + UV lamp }\end{array}$ & 1 year \\
\hline \multirow{7}{*}{ Slide } & Yes & $\begin{array}{c}\text { gravel+sand+ } \\
\text { hydroanthracite }\end{array}$ & $\begin{array}{c}\text { sodium hypochlorite } \\
\text { + UV lamp }\end{array}$ & 1 year \\
\cline { 2 - 6 } & Sport & Yes & diatomaceous & sodium hypochlorite & 2 months \\
\cline { 2 - 6 } & Recreational & Yes & diatomaceous & sodium hypochlorite & 2 months \\
\cline { 2 - 6 } & Children's & Yes & diatomaceous & sodium hypochlorite & 2 months \\
\cline { 2 - 6 } & Water Slide & Yes & diatomaceous & sodium hypochlorite & 2 months \\
\hline
\end{tabular}


The collected water samples were subjected to chromatographic analysis using a Gas Chromatograph coupled to Mass Spectrometry (GC/MS) with Electronic Ionization, Model 7890B by Perlan Technologies. GC-MS is a highly efficient tool widely used to analyze PCPs at extremely low levels from environmental samples. It was carried out in accordance with the developed analytical procedure presented in the paper [23]. The oven temperature program was as follows: $80^{\circ} \mathrm{C}(6 \mathrm{~min}), 5^{\circ} \mathrm{C} / \mathrm{min}$ to $260^{\circ} \mathrm{C}, 20^{\circ} \mathrm{C} / \mathrm{min}$ to $300^{\circ} \mathrm{C}$. The support phase was helium with a flow of $1.1 \mathrm{~mL} / \mathrm{min}$. Sample injections of $1 \mu \mathrm{l}$ were performed automatically. The mass detector worked in the ion recording mode in the range of 50 to $700 \mathrm{~m} / \mathrm{s}$.

Solid Phase Extraction using Supelclean ${ }^{\mathrm{TM}}$ ENVI-18 Tubes from Sigma Aldrich filled with non-polar adsorbent C18 (octadecyd bonding) was aplied to isolate micropollutants from the water matrix. The bed was firstly conditioned using organic solvents of purity grade $>99.5 \%$ from Avantor Performance Materials, in sequence: $5 \mathrm{~mL}$ of methanol and $5 \mathrm{~mL}$ of acetonitrile. After conditioning, it was washed with $5 \mathrm{~mL}$ of deionized water. Then $100 \mathrm{~mL}$ of water sample was applied at a consistent and reduced flow rate of 1-2 drops/second. After extraction, the bed was dried for $5 \mathrm{~min}$ under vacuum. The extract was eluted respectively with $1.5 \mathrm{~mL}$ of acetonitrile and $1.5 \mathrm{~mL}$ of methanol.

The concentration of BZ-3 (oxybenzone) and its major metabolite, BZ-8 were measured. The standards of high purity $>98 \%$ were purchased from Sigma Aldrich. The characteristic of selected compounds are presented in Table 2.

Table 2. Compounds selected for this study.

\begin{tabular}{|c|c|c|c|c|c|c|}
\hline Nomenclature & Abbreviation & $\begin{array}{c}\text { Molecular } \\
\text { weight }\end{array}$ & $\begin{array}{c}\text { Molecular } \\
\text { formula }\end{array}$ & $\begin{array}{c}\text { CAS } \\
\text { number }\end{array}$ & $\begin{array}{c}\text { LOD* } \\
{[\mathbf{n g} / \mathbf{L}]}\end{array}$ & $\begin{array}{c}\text { LOQ** } \\
{[\mathbf{n g} / \mathbf{L}]}\end{array}$ \\
\hline $\begin{array}{c}\text { Benzophenone-3 } \\
\text { (oxybenzone) }\end{array}$ & $\mathrm{BZ}-3$ & 228.24 & $\mathrm{C}_{14} \mathrm{H}_{12} \mathrm{O}_{3}$ & $131-57-7$ & 0.3 & 0.67 \\
\hline $\begin{array}{c}\text { Benzophenone-8 } \\
\text { (dioxybenzone) }\end{array}$ & $\mathrm{BZ}-8$ & 244.25 & $\mathrm{C}_{14} \mathrm{H}_{12} \mathrm{O}_{4}$ & $131-53-3$ & 0.1 & 0.74 \\
\hline
\end{tabular}

*LOD - Limit of Detection, it is the lowest analyte concentration likely to be reliably distinguished and at which detection is feasible [24].

**LOQ - Limit of Quantification, is the lowest concentration at which the analyte can not only be reliably detected but at which some predefined goals for bias and imprecision are met [24].

\section{Results and discussion}

The obtained profiles of GC-MS chromatograms show many resemblance between indoor swimming pool samples. Peaks of the biggest area typically appear in the similar time range. The effects of chromatogram analysis of outdoor pool samples are also comparable to others obtained from samples of this type of pool. However, the huge difference between the typical profile of GC-MS chromatograms for indoor (Fig. 1a) and outdoor (Fig. 1b) swimming pool were observed. There are many peaks obtained from the analysis of water from indoor pools, which are not present in the chromatograph profiles of outdoor swimming pool. Moreover, the peaks acquired at the same time in both types of swimming pools, are smaller for outdoor pools. There are also some peaks in chromatograms from outdoor pool, that are not observed for indoor pools. 
The conducted detailed quantitative analysis, summarized in Figure 2, show that the frequency of occurrence and concentrations of both selected compounds (BZ-3 and BZ-8) are higher in outdoor swimming pools than in indoor swimming pools. This is different than the results of Ekowati's research [8], carried out in Spain. His work showed a higher concentrations of BZ-3, BZ-8 and its more frequent occurrence in outdoor than in indoor pools (Table 3 ).

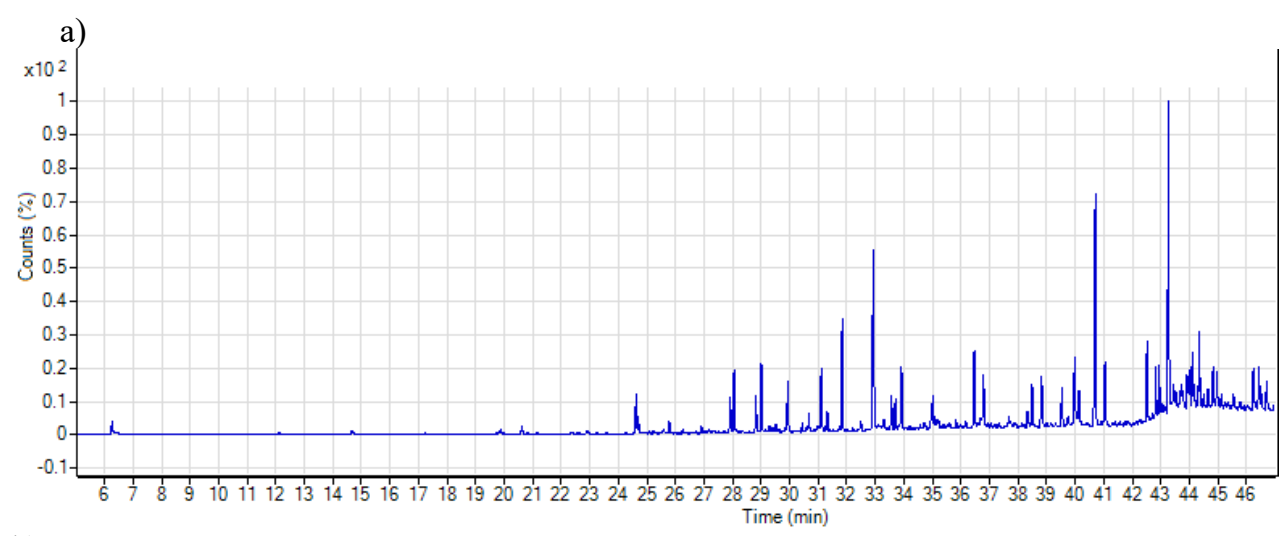

b)

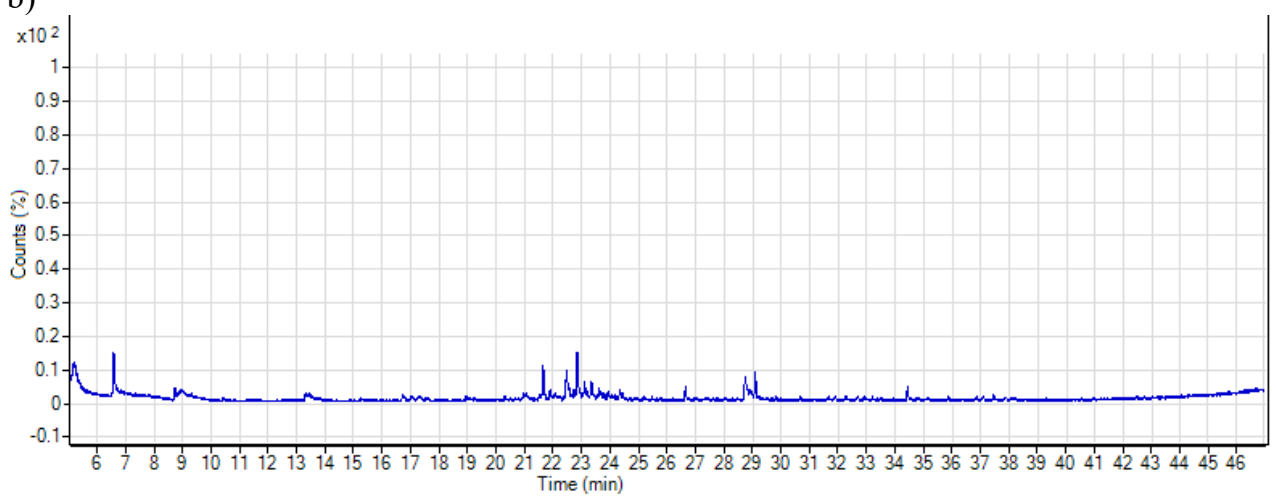

Fig. 1. Examples, selected as typical, chromatograms obtained during the analysis of water samples from a) indoor swimming pool b) outdoor swimming pool. 


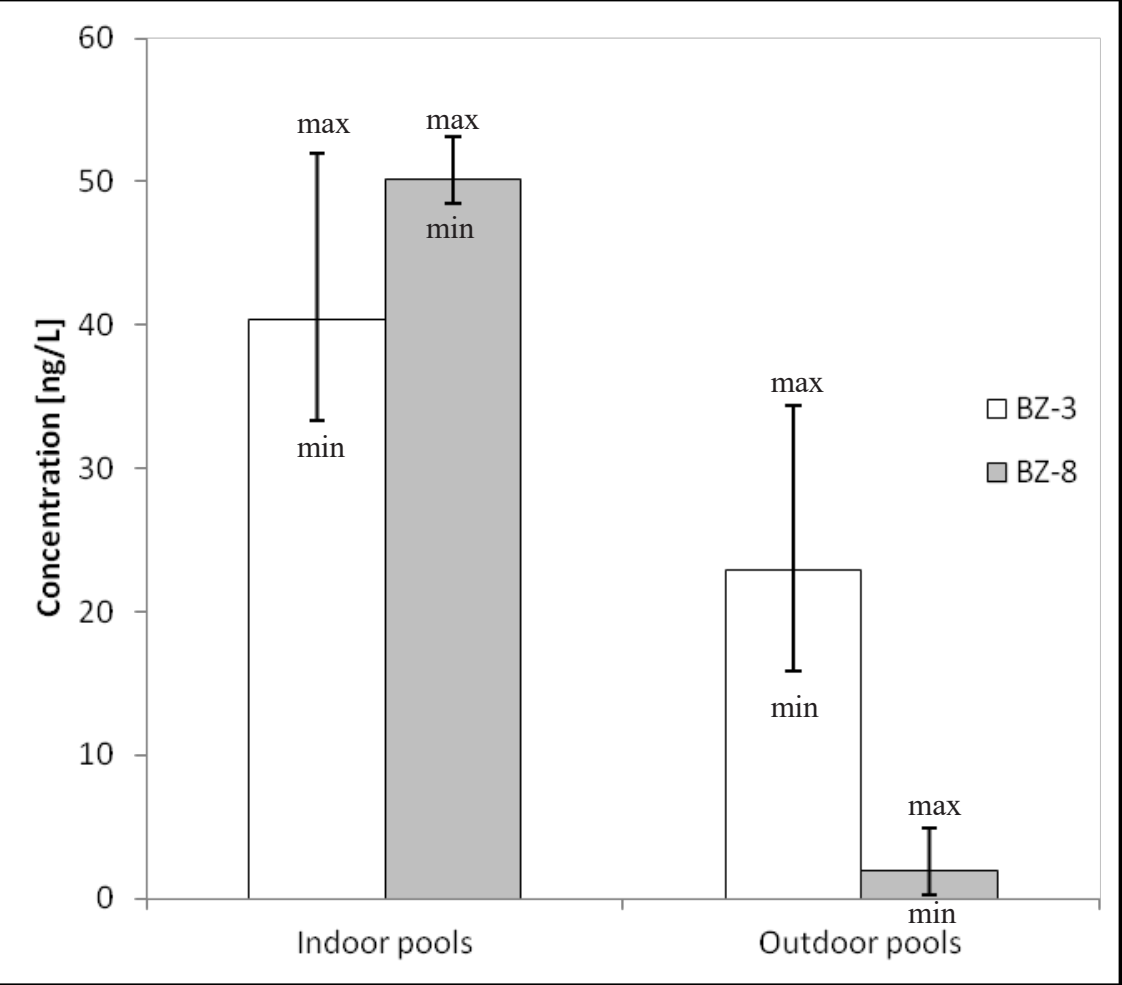

Fig. 2. Concentrations ranges and their mean value of selected compounds in outdoor and indoor swimming pools.

Table 3. Comparison of concentrations and frequency of occurrence selected PCPs in different countries.

\begin{tabular}{|c|c|c|c|c|}
\hline \multirow{2}{*}{$\begin{array}{c}\text { Type of } \\
\text { pool }\end{array}$} & \multicolumn{2}{c|}{$\begin{array}{c}\text { Concentration range } \\
\text { [ng/L] }\end{array}$} & \multicolumn{2}{c|}{$\begin{array}{c}\text { Frequency of occurrence > LOD } \\
{[\%]}\end{array}$} \\
\cline { 2 - 5 } & $\begin{array}{c}\text { This research } \\
\text { (Poland) }\end{array}$ & $\begin{array}{c}\text { Ekowati's work } \\
\text { (Spanish) [8] }\end{array}$ & $\begin{array}{c}\text { This research } \\
\text { (Poland) }\end{array}$ & $\begin{array}{c}\text { Ekowati's work } \\
\text { (Spanish) [8] }\end{array}$ \\
\hline \multicolumn{5}{|c|}{ Benzophenone-3 (oxybenzone), BZ-3 } \\
\hline Indoor & $33.4-51.7$ & $1.0-4.87$ & 23 & 7 \\
\hline Outdoor & $15.9-34.4$ & $1.27-15.17$ & 12 & 10 \\
\hline \multicolumn{2}{|c|}{ Benzophenone-8 (dioxybenzone), BZ-8 } & 27 \\
\hline Indoor & $48.5-53.2$ & $1.1-7.00$ & 66 & 48 \\
\hline Outdoor & $0.8-5.0$ & $2.3-21.60$ & 42 & \multirow{2}{*}{} \\
\hline
\end{tabular}




\section{Conclusions}

The results show that $36 \%$ of water samples contained of tested compound, a popular in sunscreens UV filter, oxybenzone or one of its major metabolite, dioxybenzone at concentration $>$ LOD. The higher concentrations and the more frequency of occurrence were obtained for indoor swimming pools than for outdoor swimming pools. This result is a bit surprising, considering that the use of sunscreens is more popular among users of outdoor pools users due to the body's' exposure to the sun. In addition, the results of the similar studies in Spain showed the opposite relationship. However, two important aspects should be noted:

- The swimming pools tested in this work differed in the type of filter beds applied in the water treatment systems, there are multilayer beds (gravel-sand-hydroanthracite) in indoor pools and diatomaceous beds in outdoor pools.

- In Poland, outdoor pools can operate only a few months a year, in summer (after this period they are emptied and refilled again the next year), while indoor pools work all year long.

The obtained results may therefore suggests that the modern diatomaceous filtration bed is more effective in the removing PCPs from water than traditional multilayer filtration bed but yet the confirmation of this requires further, extended research.

In addition, undoubtedly the working time of the swimming pool, understood as the frequency of its full water exchange, significantly affects the obtained results. This is evidenced by the completely different relationships between outdoor and indoor swimming pools in Poland and Spain. In Spain, unlike in Poland, both outdoor and indoor pools are open all year round with full water refreshment only once a year. Since the frequency of water exchange in the swimming pool affects the concentration value of selected compounds, it means that micropollutants from the PCPs group may accumulate in the swimming pools and they are not removed effectively.

This material is based on work supported by the Research Funds For Young Researchers awarded to the Institute of Water and Wastewater Engineering of the Silesian University of Technology (No. BKM/554/RIE-4/2017).

\section{References}

1. World Health Organization, Guidelines for safe recreational water environments. Volume 2. Swimming pools and similar environments (2006)

2. L.M. Suppes, R.A. Canales, C.P. Gerba, K.A. Reynolds, Int. J. Hyg. Environ. Health. 219, 8, 915-919 (2016)

3. M.Włodarczyk-Makuła, Wybrane mikrozanieczyszczenia organiczne w wodach i glebie (Wydawnictwo Politechniki Częstochowskiej, 2013)

4. D. Bledzka, J. Gromadzinska, W. Wasowicz, Environ. Int. 67, 27 (2014)

5. M. Terasaki, M. Makino, Environ. Chem. Lett. 10, 401 (2008)

6. R. Golden, J. Gandy, G. Vollmer, Crit. Rev. Toxicol. 35, 435 (2005)

7. C. Piao, L. Che, Y. Wang, J. Chromatogr. B 969, 139 (2014)

8. Y. Ekowati, G. Buttiglieri, G. Ferrero, J. Valle-Sistac, M.S. Diaz-Cruz, D. Barceló, M. Petrovic,M. Villagrasa, M.D. Kennedy, I. Rodríguez-Roda, Environ. Sci. Pollut. Res. Int. 23, 14431 (2016)

9. P. Cuderman, E. Heath, Anal. Bioanal. Chem. 387, 1343 (2007)

10. D.L. Giokas, V.A. Sakkas, T.A. Albanis, J. Chromatogr. A 1026, 289 (2005) 
11. D.L. Giokas, V.A. Sakkas, T.A. Albanis, D.A. Lampropoulou J. Chromatogr. A 1077, 19 (2005)

12. D.A. Lambropoulou, D.L., Giokas, V.A. Sakkas, T.A. Albanis, M.I. Karayannis, J. Chromatogr. A 967, 243 (2002)

13. W. Li, Y. Shi, L. Gao, J. Liu1, Y. Cai, Environ. Sci. Pollut. Res. Int. 22, 17987 (2015)

14. P.Y. Kunz, H.F. Galicia, K. Fent, Toxicol. Sci. 90, 349 (2006)

15. P.Y. Kunz, K. Fent, J. Chromatogr. A 967, 243 (2006)

16. R. Ma, B. Cotton, W. Lichtensteiger, M. Schlumpf, Toxicol. Sci. 74, 43 (2003)

17. K. Morohoshi, H. Yamamoto, R. Kamata, F. Shiraishi, T. Koda, M. Morita, Toxicol. In Vitro 19, 457 (2005)

18. M. Schlumpf, B. Cotton, M. Conscience, V. Haller, B. Steinmann, W. Lichtensteiger, Environ. Health Perspect. 109, 239 (2001)

19. T. Suzuki, S. Kitamura, R. Khota, K. Sugihara, N. Fujimoto, S. Ohta, oxicol. Appl. Pharmacol. 203, 9 (2005)

20. N.J. Lowe, Dermatol Clin. 24, 9 (2006)

21. A. Lempart, E. Kudlek, M. Lempart, M. Dudziak, J. Environ. Eng. (to be published)

22. A. Lempart, E. Kudlek, M. Dudziak, Central European Conference ECOpole'17. Abstracts, 25 (2017)

23. A. Lempart, E. Kudlek, M. Dudziak, Proceedings 2, 177 (2018)

24. D.A. Armbruster, T. Pry, Clin. Biochem. Rev. 29, 49 (2008) 